\title{
Does the brain need an enema during deep hypothermic circulatory arrest?
}

John A. Elefteriades, MD, PhD (hon), and Bulat A. Ziganshin, MD, PhD

\author{
From the Aortic Institute at Yale-New Haven Hospital, Yale University School of Medicine, New Haven, Conn. \\ Disclosures: Authors have nothing to disclose with regard to commercial support. \\ Received for publication May 21, 2018; revisions received May 21, 2018; accepted for publication May 23, 2018; \\ available ahead of print July 4, 2018. \\ Address for reprints: John A. Elefteriades, MD, PhD (hon), Aortic Institute at Yale-New Haven Hospital, Yale \\ University School of Medicine, 789 Howard Ave, Clinic Building CB317, New Haven, CT 06519 (E-mail: \\ john.elefteriades@yale.edu). \\ J Thorac Cardiovasc Surg 2018;156:1349-50 \\ $0022-5223 / \$ 36.00$ \\ Copyright $\odot 2018$ Published by Elsevier Inc. on behalf of The American Association for Thoracic Surgery \\ https://doi.org/10.1016/j.jtcvs.2018.05.091
}

We are pleased to comment on the article, "Adjunct Retrograde Cerebral Perfusion Provides Superior Outcomes Compared With Hypothermic Circulatory Arrest Alone: A Meta-Analysis," by Tian and colleagues, ${ }^{1}$ appearing in this issue of the Journal.

Dr Denton Cooley famously referred to retrograde cardioplegia as "an enema of the heart"-reflecting without camouflage his disfavor of that technique for protection of the heart during ischemia. The article by Tian and colleagues ${ }^{1}$ examines a similar issue of backwards perfusion of, not the heart, but rather the brain during the global ischemia of deep hypothermic arrest.

Tian and colleagues ${ }^{1}$ have done a superb job of addressing this issue through meta-analysis. Their study involved an extreme amount of work in identifying, examining, categorizing, and analyzing nearly 1000 studies that report clinical results after aortic arch operations done with straight deep hypothermic circulatory arrest (HCA) or deep HCA supplemented by retrograde cerebral perfusion (HCA + RCP). They applied advanced meta-analytic techniques to the distillate of most relevant and most complete articles. For this tremendous effort, the aortic surgical community is grateful.

The meta-analysis reveals that (1) $\mathrm{HCA}+\mathrm{RCP}$ leads to lower operative mortality, and (2) HCA + RCP leads to lower perioperative stroke rate. These are important findings. The lower operative mortality disappears when meta-regression statistical techniques are applied, however, and the stroke benefit disappears when only medium- to high-quality studies are included in the meta-analysis. Wikipedia defines meta-regression techniques as "a tool used in meta-analysis to examine the impact of moderator variables on study effect size using regression-based techniques." 2 Thus the main findings of this study, although meaningful, are not statistically robust.

The meticulous review conducted by Tian and colleagues ${ }^{1}$ identified only 2 randomized, controlled trials, which totaled only 31 patients in each arm of the study

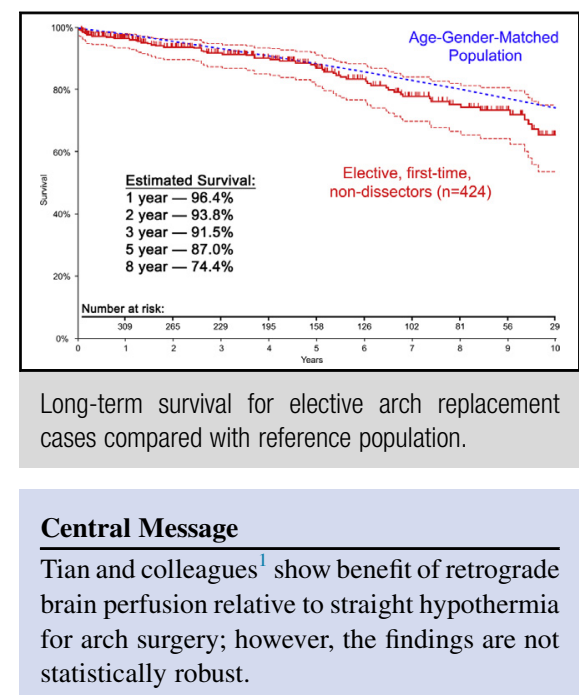

See Article page 1339.

(only $1.1 \%$ of the entire meta-analysis). The remaining studies were retrospective and observational in nature.

We have published extensively on aortic arch surgery, demonstrating high safety in terms of mortality and stroke. ${ }^{3,4}$ In our articles published in The Journal of Thoracic and Cardiothoracic Surgery in 2014 and 2017, we found low mortality $(2.9 \%)$, low stroke rate $(2.0 \%)$, and excellent long-term survival (Figure 1). In our experience, neither antegrade nor retrograde brain perfusion has been necessary to secure good clinical outcomes. Straight

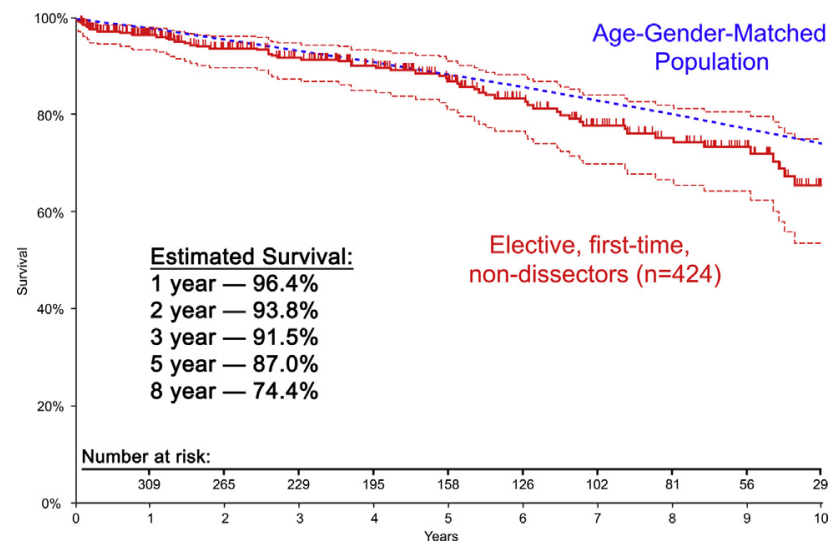

FIGURE 1. Long-term survival of patients undergoing elective aortic arch surgery under straight deep hypothermic circulatory arrest is not statistically different from that of an age- and sex-matched control population. Reprinted with permission. ${ }^{4}$ 
deep HCA has afforded us a clean, bloodless, clutter-free surgical field. That said, we have no objection to adjunctive brain perfusion, whether antegrade or retrograde.

Our Journal-published experience of 613 patients was not included among the studies tabulated in this metaanalysis. Our article seems to meet all the criteria outlined by Tian and colleagues ${ }^{1}$ (human study, English language, adult patients, arch surgery, either HCA or HCA + RCP, specific primary outcome data) except for the lack of patients in the RCP category (we used only deep HCA in all patients). Our article, were it included, would have expanded the HCA group in the Tian and colleagues ${ }^{1}$ article by more than $30 \%$ - and likely skewed the mortality and stroke comparisons into "nonsignificant" territory.

In an effort to generate more generalizable data in regard to the cerebral protection techniques, Drs Tian and Yan have devised and launched a multicenter registry - the International Aortic Arch Surgery Study Group (IAASSG) ${ }^{5}-$ which may help elucidate the specific benefits of each cerebral protection strategy. We look forward to studies from the IAASSG evaluating the risks and benefits of
HCA alone compared with the perfusion strategies, and specifically RCP.

We thank Tian and colleagues ${ }^{1}$ for their important contribution, which adds additional clarity to a surgical controversy in which a specific surgeon's practice pattern seems to be determined (appropriately) in large part by his or her individual training and experience.

\section{References}

1. Tian DH, Weller J, Hasmat S, Oo A, Forrest P, Kiat H, et al. Adjunct retrograde cerebral perfusion provides superior outcomes compared with hypothermic circulatory arrest alone: a meta-analysis. J Thorac Cardiovasc Surg. 2018;156:1339-48.

2. Wikipedia.org. Meta-regression. Available at: https://en.wikipedia.org/wiki/Metaregression. Accessed August 25, 2017.

3. Ziganshin BA, Rajbanshi BG, Tranquilli M, Fang H, Rizzo JA, Elefteriades JA. Straight deep hypothermic circulatory arrest for cerebral protection during aortic arch surgery: safe and effective. J Thorac Cardiovasc Surg. 2014;148:888-98; discussion 898-900.

4. Damberg A, Carino D, Charilaou P, Peterss S, Tranquilli M, Ziganshin BA, et al. Favorable late survival after aortic surgery under straight deep hypothermic circulatory arrest. J Thorac Cardiovasc Surg. 2017;154:1831-9.e1.

5. Yan TD, Tian DH, LeMaire SA, Misfeld M, Elefteriades JA, Chen EP, et al. The ARCH projects: design and rationale (IAASSG 001). Eur J Cardiothorac Surg. 2014;45:10-6. 